\title{
Impacts of the COVID-19 Pandemic on Mental Health and Potential Solutions in Different Members in an Ordinary Family Unit
}

\author{
Limin Wang, Ghulam Nabi, Lirong Zuo, Yuefeng Wu and Dongming Li* \\ Ministry of Education Key Laboratory of Molecular and Cellular Biology, Key Laboratory of Animal Physiology, Biochemistry \\ and Molecular Biology of Hebei Province, College of Life Sciences, Hebei Normal University, Shijiazhuang, China
}

Keywords: COVID-19, ordinary family members, mental health disorders, crisis intervention measures, family unit

\section{INTRODUCTION}

Coronavirus disease 2019 (COVID-19) was first reported in Wuhan City, China, in December 2019 (1). Owing to the exceptionally rapid transmission and robust infectiousness of the severe acute respiratory syndrome coronavirus 2 (SARS-CoV-2), and its high mortality and morbidity, the COVID-19 pandemic has swiftly led to a global public health crisis. As of November 3, 2021, there were $\sim 248.007$ million confirmed cases and over 5.0 million deaths in more than 200 countries worldwide (2).

COVID-19 has not only significantly affected the physical health of tens of millions of people worldwide but also affected individuals' mental health. Fear of the unknown virus, massive and long-term quarantine measures and economic losses, lack of basic supplies, cancelation of public events, and closing mass transit systems resulting from isolation have exacerbated stress and anxiety among the public, thus increasing individuals' risk of developing psychological disorders (3-6). According to the World Health Organization report on August 27, 2020, COVID-19 has affected the mental health of millions of people worldwide (7).

Since the outbreak of COVID-19, the mental health of medical workers and patients has been under intense scrutiny, and they have received a variety of psychological counseling and other treatments $(8,9)$. However, the mental health of the general population has received little attention concerning in comparison to healthcare workers and patients. To illustrate the public's psychological responses, we reviewed the potential causes and consequences of the adverse impacts of COVID-19 on the mental health of older adults, working adults, children and adolescents, and pregnant women by simulating an ordinary family unit, and put forward a series of targeted psychological crisis intervention measures. These addressed mental health issues would contribute to taking appropriate psychological interventions by the governments based on the characteristics of age-dependent groups. In fact, people of different ages experienced distinct psychological distress and emotional responses to the ongoing COVID-19 pandemic because they play different roles in a family.

\section{OLDER ADULTS}

According to statistics from the Chinese Center for Disease Control and Prevention (China CDC), in the confirmed COVID-19 cases, the risk of prevalence and death rates increase with advancing age, i.e., the prevalence rate of people over 50-years-old in China was 53.6\%. More seriously, the death rate for people over 50 -years-old was $93.7 \%$ among 1,023 deaths (10).

Older adults are relatively psychologically fragile and vulnerable to the influence of the external environment, while the high morbidity rate and high mortality rate of the pandemic among the 


\section{COVID-19 Pandemic}
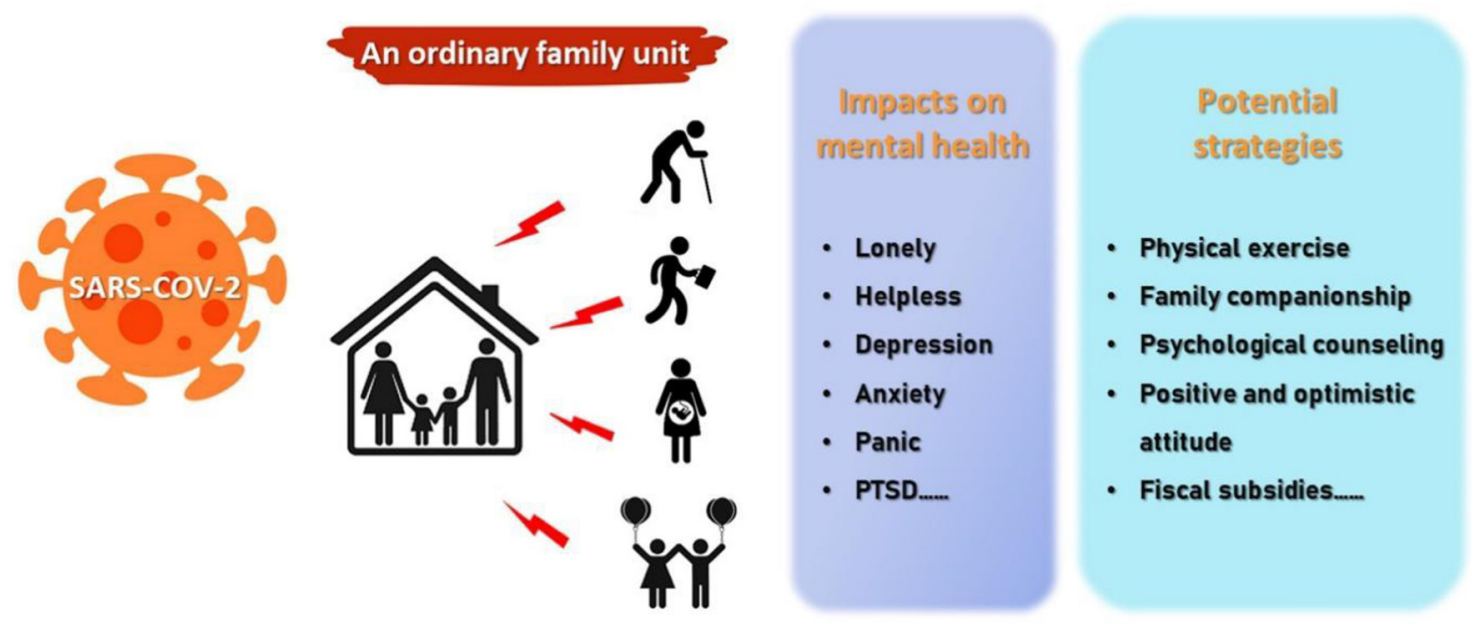

GRAPHICAL ABSTRACT | The effects of COVID-19 pandemic on mental health and corresponding solutions in different family members.

elderly further increase their psychological stress (11). First, over the past century, the sharp growth of aging populations has resulted in more aged people living alone. Aged people are more prone to have lonely and helpless feelings owing to a lack of emotional support from their children. Such feelings could be exacerbated and even result in mental disorders during the COVID-19 pandemic (11). Second, aging has been a major risk factor for chronic diseases, including cardiovascular diseases, diabetes, cancer, and neurodegenerative diseases $(12,13)$. These common morbidities render aged people more susceptible to the SARS-CoV-2 virus. However, owing to the isolation at home during the pandemic and the inability to go to the hospital for treatment, many older adults with chronic age-related diseases are more worried about their physical health, which further aggravates the prevalence of mental illness $(12,14)$. Third, as mandatory quarantine measures are taken, older adults may show a series of psychological disorders when changing their daily routines, such as reducing outdoor activities and social interactions during the COVID-19 pandemic $(3,11)$. Finally, containing the spread of the virus has entailed a dramatic shift from face-to-face to remote consulting for mental health professionals (11). Unfortunately, few older people are proficient in using internet services, which poses great challenges to their ability to access mental health services.

To lessen the potential impacts of psychological health and mental stress associated with the ongoing COVID-19 pandemic on aged people, several measures should be considered by family members and local governments. First, older adults could live together with their families to facilitate timely emotional communication and reduce loneliness. Alternatively, elders can also stay connected to friends and family members via traditional means (wired phones and letters) or advanced means (email,
WeChat, online voice, and video chat) of communication $(11,15)$. Second, through community-based integrated care approaches, regular medical care and protective measures for those with chronic age-related diseases should be provided by community-based resources such as social services. Furthermore, timely and effective communication and targeted psychological interventions among multidisciplinary mental health teams about COVID-19 should be provided for elderly patients with persistent psychological symptoms. Third, occupational health experts can encourage the elderly to exercise to release their worries and anxiety and improve their immunity and cognitive performance (16). Elders should also be encouraged to obtain information from multiple regular media resources, such as television, newspapers, and radio, to relieve their anxieties and worries (17).

\section{WORKING ADULTS}

In most ordinary families, the mental health of working adults can be easily overlooked during the pandemic. However, when facing unprecedented uncertainties, they may suffer great psychological pressure. First, the COVID-19 outbreak triggered a global economic recession, causing many unemployed or underemployed (18-20). Second, due to the stay-at-home policy during the pandemic in many countries, it is estimated that approximately one-half of the companies had more than $80 \%$ of their employees working from home during the early stages of the COVID-19 pandemic (20). Against this backdrop, both the limitations of the workspace and lack of positive social interaction are likely to have side effects that further aggravate people's stress (3). In China, an increasing number of adults 
are facing severe financial pressures, and some adults even cannot pay for basic requirements, including housing, food, and healthcare $(21,22)$. Such direct threats to the livelihood of working adults may harm their mental health more so than the ongoing disease itself. Third, a surge in domestic violence has been reported amidst the COVID-19 pandemic. Especially for females, employment and income source act as a buffer against violence; unemployment takes off this buffer and makes them vulnerable to violence at the hands of spouses (23). According to statistics from the National Commission for Women, India, there has been a $100 \%$ increase in complaints related to violence against women after the nationwide lockdown was imposed in just 1 month (24). Finally, a return-to-work policy in many countries has been employed to compensate for the economic loss caused by the outbreak. However, the proportion of confirmed infections in many working adults has increased remarkably (25); therefore, for working adults, returning to work may increase their risk of infection, which will exacerbate their psychological burdens. Economic losses, family burdens, and domestic violence may lead to stress, anxiety, and other mental illnesses.

Given that the threats of psychological health deterioration to working adults cannot be neglected when we are fighting against the COVID-19 pandemic, several measures need to be implemented. First, people's financial losses should be identified during the isolation period by relevant government departments, and relief supplies and financial subsidies must be provided on a timely basis. Furthermore, the government should create more job positions for those who are unemployed or underemployed as soon as possible. In addition, for those who have changed their working style, it is necessary to help them get used to the new way of working and improve their ability and quality in time. Working adults should return to work in an orderly and periodic manner with governmental permission, as long as the COVID-19 pandemic is effectively controlled. Third, community social workers can play an active role in helping people cope with family issues (17). Besides, community psychological interventions and support might have some effects in reducing depressive and anxiety symptoms in adults during these stressful events (17). Notably, social support was the most important protective factor against psychological sequelae of the COVID-19 pandemic in working adults. It has been proposed that high-quality social support from family members and friends may alleviate anxiety and worry and enhance psychological and social relationships (26-29).

\section{CHILDREN AND ADOLESCENTS}

Among children and adolescents, the confirmed COVID-19 cases and death cases are less prevalent $(2.1 \%$ of 44,672 confirmed cases) and less lethal ( $0.1 \%$ of 1,023 deaths) in China (10). Similar findings have been reported in other countries with more severe outbreaks (30). However, although the prevalence of COVID-19 among children is low, the extensive impact of the pandemic on children's mental health cannot be ignored. First, the periods of children and adolescents face a high degree of vulnerability to adverse environmental conditions (31), and the relative immaturity of the brain may make it particularly sensitive to stress-induced dysfunctions, with both immediate and lasting consequences on mental health (32). Second, to prevent the further spread of COVID-19, many countries have ordered school closures as an emergency solution $(3,4)$. Prolonged school closure can disrupt the normal social activities of young people with their classmates and teachers, which can have serious negative effects on their mental health, such as causing social phobia, anxiety, restlessness, and autism spectrum disorder (3, 33). Third, with many classes switched from offline to online, young people are spending significantly more time online, increasing their dependency on the internet (34). Additionally, internet engagement has increased among students because face-to-face interaction and activities are restricted. Students are more likely to be engaging in other online activities such as social media use and online gaming, which may be associated with internet addiction $(35,36)$. All these changes also exacerbate the conflicts between parents and children, which are associated with an increased risk of stress-related mental illness (37). In addition, children's ability to access too much information about the pandemic (infodemic) over the internet could easily cause panic (15).

Thus, close attention to children and adolescents is required to address these emergency issues effectively and avoid any long-term negative consequences for the rest of their lives. First, some low-risk areas began a phased resumption of classes with the outbreak under the initial control, which allowed children to play with their friends. Second, parents' supervision and guidance should be strengthened to prevent children from excessive internet use. Significantly, parents need to communicate more with their children to avoid further intensification of conflicts. Finally, to reduce children's excessive access to pandemic information by controlling their online time, parents should also keep a positive and optimistic attitude to avoid negative emotions affecting their children. Additionally, it is important to consider post-pandemic surveillance of mental disorders among children and adolescents (38). Furthermore, children and adolescents should stay physically active and engage in regular exercise to avoid the risk of physical and mental ill-health (38-42).

\section{PREGNANT WOMEN}

Relevant studies indicated that pregnant women may be more susceptible to COVID-19 $(43,44)$. As special members of the families, therefore, we should also pay close attention to the psychological status of pregnant women during the pandemic. First, gestation is a time of significant psychological and physiological vulnerabilities; the higher psychosocial stress during this period can increase susceptibility to several mental disorders, including schizophrenia, mood disorders, high levels of anxiety, and autism (45). Second, during an 


\section{Family Problems}

- Reduced social interactions (lonely)

si

Older adults

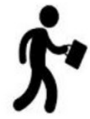

Working adults

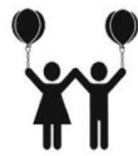

Children and adolescents

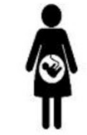

Pregnant women
- Psychological fragility (helpless)

- Daily routines changed

- Not proficient in using the internet

- Financial pressures

- Work pattern changed

- Family burden of caring for the elderly and children

- Fear of being infected after returning to work (anxiety)

- Interrupted normal social activities (social phobia and PTSD)

- Internet addiction

- Exaggerated and false information about the epidemic (panic)

- Unable to conducted routine antenatal examinations and delivery

- Maternal stress can directly affect the development of the fetus

- Worry babies will become infected

- Postpartum depression

\section{Strategies}

- Emotional communication with families or friends

- Regular medical care and persistent psychological counseling

- Simple physical exercise

- Obtain information from multiple traditional media resources

- Fiscal subsidies and re-employment

- Improve personal ability and quality in time to get used to the new way of working

- Strengthen community service capacity

- Return to work in an orderly manner with the government's permission.

- Strengthen parents' supervision and guidance function

- Parents need to communicate more with their children

- Parents should keep a positive and optimistic attitude

- Home antenatal examinations and delivery services provided by the specialized medical team

- Family companionship and psychological counseling

- Limit the number of people gathered

- Online mental health services

FIGURE 1 | Impacts of the COVID-19 pandemic on individuals' mental health and corresponding strategies for mitigating these adverse effects among a stimulated ordinary family unit.

outbreak, owing to the high potential risk of exposure to SARS-COV-2 in the hospital environment and the strict quarantine policy, many pregnant women were unable to conduct routine antenatal examinations or delivery, which may make them feel highly stressed and anxious $(45,46)$. Furthermore, some pregnant women worry that their babies will be infected after they are born during a pandemic. These fears have further deepened the postpartum anxiety of pregnant women $(43,44)$. Most noteworthy, the higher maternal psychosocial stress during gestation can directly affect the development of the fetus (47). A series of studies worldwide have reported a significant rise in the proportion of preterm (43) and stillbirth $(48,49)$ in pregnant women since the COVID-19 pandemic started. In addition, COVID-19 can also affect the health and well-being of mothers and their newborns by altering immune responses at the maternal-fetal interface (43).

In sum, owing to women being fragile physical condition during pregnancy, isolation at home for a long time, and worrying about one's baby, an increase in postpartum depression and other psychological problems is likely (46). Therefore, effective measures should be adopted to relieve the stress and anxiety of pregnant women. First, when the pandemic hit, some face-to-face consultations were substituted with online remote appointments to protect pregnant women from the coronavirus. However, medical workers cannot directly measure some critical physiological indicators of pregnant women, such as blood pressure, babies' heartbeat, and development status. Therefore, home antenatal examinations and delivery services should be provided by a specialized medical team to reduce visits to high-risk areas such as hospitals (46, 50). Second, during pregnancy, family companionship and psychological counseling are necessary, which can effectively reduce the psychological pressure on pregnant women. Moreover, to protect newborns, a mother should limit the number of people they have contact with (44). Finally, other online strategies, such as online mental health services or telemedicine, can help alleviate the psychological 
problems of pregnant women by communicating with others remotely (51-53).

\section{CONCLUSION}

Among the general public, the sudden outbreak and prolonged duration of the COVID-19 pandemic have led to a series of adverse mental health problems. Given that there was limited information regarding mental health issues related to infectious diseases in past epidemics and pandemics, the general population received little attention concerning the diverse psychological impacts and mental health disorders. We analyzed the potential causes and consequences of the pandemic on mental health in different populations in an ordinary family unit with older adults, working adults, children and adolescents, and pregnant women, and then addressed several specific solutions to lessen the mental stress caused by the COVID-19 pandemic for each group (Figure 1). This information would contribute to establishing universal protocols and guidelines for the future, and inform appropriate and feasible guidance for successfully preventing the ongoing pandemic-related mental health problems to

\section{REFERENCES}

1. Khan S, Nabi G, Han G, Siddique R, Lian S, Shi H, et al. Novel coronavirus: how things are in Wuhan. Clin Microbiol Infec. (2020) 26:399400. doi: 10.1016/j.cmi.2020.02.005

2. Johns Hopkins Coronavirus Resource Center (2021). Available online at: https://coronavirus.jhu.edu/ (accessed November 3, 2021).

3. Brooks SK, Webster RK, Smith LE, Woodland L, Wessely S, Greenberg N, et al. The psychological impact of quarantine and how to reduce it: rapid review of the evidence. Lancet. (2020) 395:912-20. doi: 10.1016/S0140-6736(20)30460-8

4. Duan L, Zhu G. Psychological interventions for people affected by the COVID-19 epidemic. Lancet Psychiatry. (2020) 7:3002. doi: 10.1016/S2215-0366(20)30073-0

5. Javed B, Sarwer A, Soto EB, Mashwani ZU. Impact of SARS-CoV-2 (Coronavirus) pandemic on public mental health. Front Public Health. (2020) 8:292. doi: 10.3389/fpubh.2020.00292

6. Wang LM, Nabi G, Zhang TH, Wu YF, Li DM. Potential neurochemical and neuroendocrine effects of social distancing amidst the COVID-19 pandemic. Front Endocrinol. (2020) 11:582288. doi: 10.3389/fendo.2020.582288

7. World Health Organization. Tedros: Lack of Social Interaction During the Epidemic Has an Impact on Mental Health. Geneva: WHO (2020). Available online at: https://covid19.who.int (accessed August 28, 2020).

8. Bo HX, Li W, Yang Y, Wang Y, Zhang Q, Cheung T, et al. Posttraumatic stress symptoms and attitude toward crisis mental health services among clinically stable patients with COVID-19 in China. Psychol Med. (2020) 27:1-2. doi: 10.1017/S0033291720000999

9. Cao JY, Wei J, Zhu HD, Duan YP, Geng WQ, Hong X, et al. A study of basic needs and psychological well being of medical workers in the fever clinic of a tertiary general hospital in Beijing during the CoVID-19 outbreak. Psychother Psychosom. (2020) 89:252-4. doi: 10.1159/000507453

10. China CDC. The novel coronavirus pneumonia emergency response epidemiology team. Vital surveillances: the epidemiological characteristics of an outbreak of 2019 novel coronavirus diseases (COVID-19). China CDC Weekly. (2020) 2:113-22. doi: 10.46234/ccdcw2020.032

11. Yang Y, Li W, Zhang Q, Zhang L, Cheung T, Xiang YT. Mental health services for older adults in China during the COVID-19 outbreak. Lancet Psychiatry. (2020) 7:e19. doi: 10.1016/S2215-0366(20)30079-1

12. Partridge L, Deelen J, Slagboom PE. Facing up to the global challenges of ageing. Nature. (2018) 561:45-56. doi: 10.1038/s41586-018-0457-8 minimize the adverse impacts of the COVID-19 pandemic on mental health.

\section{AUTHOR CONTRIBUTIONS}

LW and GN: investigation and writing-original draft preparation. LZ: investigation. DL: writing-review and editing. DL and YW: conceptualization, supervision, and funding acquisition. All authors contributed to the article and approved the submitted version.

\section{FUNDING}

This work was supported by the National Natural Science Foundation of China (NSFC, Grant No. 31770445) to YW, and NSFC (Grant No. 31672292) and the Natural Science Foundation of Hebei Province (NSFHB, Grant No. C2020205038) to DL, and NSFHB (Grant No. C2020205005) and China Post doctoral Science Foundation (Grant No. 2020M670685) and the Postdoctoral Research Program of Hebei Normal University to LW.

13. Yang XB, Yu Y, Xu JQ, Shu HQ, Xia JA, Liu H, et al. Clinical course and outcomes of critically ill patients with SARS-CoV-2 pneumonia in Wuhan, China: a single-centered, retrospective, observational study. Lancet Respir Med. (2020) 8:475-81. doi: 10.1016/S2213-2600(20)30079-5

14. Zhang Q, Song WH. The challenges of the COVID-19 pandemic: approaches for the elderly and those with Alzheimer's disease. MedComm. (2020). 1:6973. doi: $10.1002 / \mathrm{mco} 2.4$

15. World Health Organization. Mental Health Psychosocial Considerations During the COVID-19 Outbreak. Geneva: WHO (2020). Available online at: https://covid19.who.int

16. Tyndall AV, Clark CM, Anderson TJ, Hogan DB, Hill MD, Longman RS, et al. Protective effects of exercise on cognition and brain health in older adults. Exerc Sport Sci Rev. (2018) 46:215-23. doi: 10.1249/JES.0000000000000161

17. Razai MS, Oakeshott P, Kankam H, Galea S, Stokes-Lampard H. Mitigating the psychological effects of social isolation during the covid-19 pandemic. BMJ. (2020) 369:m1904. doi: 10.1136/bmj.m1904

18. Couch KA, Fairlie RW, Xu HN. Early evidence of the impacts of COVID-19 on minority unemployment. J Public Econ. (2020) 192:104287. doi: 10.1016/j.jpubeco.2020.104287

19. OECD. Unprecedented Falls in GDP in Most G20 Economies in Second Quarter of 2020. OECD (Economy) (2020). Available online at: https://www.oecd. org/economy/g20-gdp-growth-second-quarter-2020-oecd.htm (accessed September 14, 2020).

20. Kniffin KM, Narayanan J, Anseel F, Antonakis J, Ashford SP, Bakker AB, et al. COVID-19 and the workplace: implications, issues, and insights for future research and action. Am Psychol. (2021) 76:63-77. doi: 10.1037/amp0000716

21. Ayittey FK, Ayittey MK, Chiwero NB, Kamasah JS, Dzuvor C. Economic impacts of Wuhan 2019-nCoV on China and the world. J Med Virol. (2020) 92:473-5. doi: 10.1002/jmv.25706

22. Guo J, Feng XL, Wang XH, van IJzendoorn MH. Coping with COVID-19: exposure to COVID-19 and negative impact on livelihood predict elevated mental health problems in Chinese adults. Int J Env Res Public Health. (2020) 17:3857. doi: 10.3390/ijerph17113857

23. Vora M, Malathesh BC, Das S, Chatterjee SS. COVID-19 and domestic violence against women. Asian J Psychiatr. (2020) 53:102227. doi: 10.1016/j.ajp.2020.102227

24. Chandra J. NCW Launches Domestic Violence Helpline. The Hindu. (2020). Available online at: https://www.thehindu.com/news/national/ncw-launchesdomestic-violence-helpline/article31312219.ece (accessed April 29, 2020). 
25. Larochelle MR. "Is it safe for me to go to work?" risk stratification for workers during the COVID-19 pandemic. N Engl J Med. (2020) 383:e28. doi: 10.1056/NEJMp2013413

26. Ozbay F, Johnson DC, Dimoulas E, Morgan CA, Charney D, Southwick S. Social support and resilience to stress: from neurobiology to clinical practice. Psychiatry. (2007) 4:35-40.

27. Grey I, Arora T, Thomas J, Saneh A, Tohme P, Abi-Habib R. The role of perceived social support on depression and sleep during the COVID-19 pandemic. Psychiatry Res. (2020) 293:113452. doi: 10.1016/j.psychres.2020.113452

28. Woon LS, Mansor NS, Mohamad MA, Teoh SH, Leong Bin Abdullah MFI. Quality of life and its predictive factors among healthcare workers after the end of a movement lockdown: the salient roles of COVID-19 stressors, psychological experience, and social support. Front Psychol. (2021) 12:652326. doi: 10.3389/fpsyg.2021.652326

29. Woon LS, Sidi H, Nik Jaafar NR, Leong Bin Abdullah MFI. Mental health status of university healthcare workers during the COVID-19 pandemic: a post-movement lockdown assessment. Int J Environ Res Public Health. (2020) 17:9155. doi: 10.3390/ijerph17249155

30. Licciardi F, Giani T, Baldini L, Favalli EG, Caporali R., Cimaz R. COVID-19 and what pediatric rheumatologists should know: a review from a highly affected country. Pediatr Rheumatol. (2020) 18:35. doi: 10.1186/s12969-020-00422-z

31. Dahl RE. Adolescent brain development: a period of vulnerabilities and opportunities. Ann N $\quad Y$ Acad Sci. (2004) 1021:122. doi: 10.1196/annals.1308.001

32. Eiland L, Romeo RD. Stress and the developing adolescent brain. Neuroscience. (2013) 249:162-71. doi: 10.1016/j.neuroscience.2012.10.048

33. Patel K. Mental health implications of COVID-19 on children with disabilities. Asian J Psychiatr. (2020) 54:102273. doi: 10.1016/j.ajp.2020.102273

34. Shehata WM, Abdeldaim DE. Internet addiction among medical and non-medical students during COVID-19 pandemic, Tanta University, Egypt. Environ Sci Pollut Res Int. (2021) 28:5994552. doi: $10.1007 / \mathrm{s} 11356-021-14961-9$

35. Király O, Potenza MN, Stein DJ, King DL, Hodgins DC, Saunders $\mathrm{JB}$, et al. Preventing problematic internet use during the COVID19 pandemic: consensus guidance. Compr Psychiatry. (2020) 100:152180. doi: 10.1016/j.comppsych.2020.152180

36. Higuchi S, Mihara S, Kitayuguchi T, Miyakoshi H, Ooi M, Maezono M, et al. Prolonged use of internet and gaming among treatment seekers arising out of social restrictions related to COVID-19 pandemic. Psychiatry Clin Neurosci. (2020) 74:607-8. doi: 10.1111/pcn.13127

37. Chung G, Lanier P, Wong PYJ. Mediating effects of parental stress on harsh parenting and parent-child relationship during Coronavirus (COVID-19) pandemic in Singapore. J Fam Violence. (2020) 2:1-12. doi: 10.1007/s10896-020-00200-1

38. Guido CA, Amedeo I, Avenoso F, Bruni J, Zicari AM, Loffredo L, et al. Risk factors and mental health promotion strategies in children during COVID-19. Front Public Health. (2020) 8:580720. doi: 10.3389/fpubh.2020.580720

39. Herbert C, Gilg V, Sander M, Kobel S, Jerg A, Steinacker JM. Preventing mental health, well-being and physical activity during the corona pandemicrecommendations from psychology and sports medicine. Dtsch $Z$ fur Sportmed. (2020) 71:249-57. doi: 10.5960/dzsm.2020.458

40. Ammar A, Mueller P, Trabelsi K, Chtourou H, Boukhris O, Masmoudi L, et al. Psychological consequences of COVID-19 home confinement: the ECLB-COVID19 multicenter study. PLoS ONE. (2020) 15:e240204. doi: 10.1371/journal.pone.0240204

41. Ammar A, Brach M, Trabelsi K, Chtourou H, Boukhris O, Masmoudi L, et al. Effects of COVID-19 home confinement on eating behaviour and physical activity: results of the ECLB-COVID19 international online survey. Nutrients. (2020) 12:1583. doi: $10.3390 /$ nu12061583
42. Khan S, Siddique R, Bai Q, Liu Y, Xue M, Nabi G, et al. Coronaviruses disease 2019 (COVID-19): causative agent, mental health concerns, and potential management options. J Infect Public Heal. (2020) 13:18404. doi: 10.1016/j.jiph.2020.07.010

43. Liu JJ, Bao Y, Huang X, Shi J, Lu L. Mental health considerations for children quarantined because of COVID-19. Lancet Child Adolesc. (2020) 4:347-9. doi: 10.1016/S2352-4642(20)30096-1

44. $\mathrm{Lu} \mathrm{Q}$, Shi Y. Coronavirus disease (COVID-19) and neonate: what neonatologist need to know. J Med Virol. (2020) 92:5647. doi: $10.1002 /$ jmv. 25740

45. Lebel C, MacKinnon A, Bagshawe M, Tomfohr-Madsen L, Giesbrecht G. Elevated depression and anxiety symptoms among pregnant individuals during the COVID-19 pandemic. J Affect Disord. (2020) 277:5-13. doi: 10.1016/j.jad.2020.07.126

46. Rashidi FF, Simbar M. Coronavirus pandemic and worries during pregnancy; a letter to editor. Arch Acad Emerg Med. (2020) 8:e21. doi: $10.22037 /$ aaem.v8i1.598

47. Qiao Y, Wang J, Li J, Wang J. Effects of depressive and anxiety symptoms during pregnancy on pregnant, obstetric and neonatal outcomes: a follow-up study. J Obstet Gynaecol. (2012) 32:237-40. doi: 10.3109/01443615.2011.647736

48. Khalil A, von Dadelszen P, Draycott T, Ugwumadu A, O’Brien P, Magee L. Change in the incidence of stillbirth and preterm delivery during the COVID19 pandemic. JAMA. (2020) 324:705-6. doi: 10.1001/jama.2020.12746

49. Kumari V, Mehta K, Choudhary R. COVID-19 outbreak and decreased hospitalisation of pregnant women in labour. Lancet Glob Health. (2020) 8:1116-7. doi: 10.1016/S2214-109X(20)30319-3

50. Nabi G, Siddique R, Xiaoyan W, Ullah R, Nawsherwan, Xue M, et al. COVID-19 induced psychosocial stressors during gestation: possible maternal and neonatal consequences. Curr Med Res Opin. (2020) 36:16334. doi: 10.1080/03007995.2020.1815003

51. Xiang YT, Yang Y, Li W, Zhang L, Zhang Q, Cheung T, et al. Timely mental health care for the 2019 novel coronavirus outbreak is urgently needed. Lancet Psychiatry. (2020) 7:228-9. doi: 10.1016/S2215-0366(20) 30046-8

52. Marshall JM, Dunstan DA, Bartik W. Treating psychological trauma in the midst of COVID-19: the role of smartphone Apps. Front Public Health. (2020) 8:402. doi: $10.3389 /$ fpubh.2020.00402

53. Khan S, Siddique R, Xiaoyan W, Zhang R, Nabi G, Sohail Afzal M, et al. Mental health consequences of infections by coronaviruses including severe acute respiratory syndrome coronavirus 2 (SARS-CoV-2). Brain Behav. (2021) 11:e01901. doi: 10.1002/brb3.1901

Conflict of Interest: The authors declare that the research was conducted in the absence of any commercial or financial relationships that could be construed as a potential conflict of interest.

Publisher's Note: All claims expressed in this article are solely those of the authors and do not necessarily represent those of their affiliated organizations, or those of the publisher, the editors and the reviewers. Any product that may be evaluated in this article, or claim that may be made by its manufacturer, is not guaranteed or endorsed by the publisher.

Copyright $\odot 2022$ Wang, Nabi, Zuo, Wu and Li. This is an open-access article distributed under the terms of the Creative Commons Attribution License (CC BY). The use, distribution or reproduction in other forums is permitted, provided the original author(s) and the copyright owner(s) are credited and that the original publication in this journal is cited, in accordance with accepted academic practice. No use, distribution or reproduction is permitted which does not comply with these terms. 